\title{
Highly Sensing Properties Sensors Based On Ce-Doped ZnO and SnO2 Nanoparticles to Ethanol Gas
}

\author{
A. M. El-Sayed and S. M. Yakout \\ Inorganic Chemistry Department, National Research Centre, Cairo, Egypt \\ Correspondence should be addressed to: A. M. El-Sayed; ahmed_elsayed_3@hotmail.com \\ Received date: 26 May 2014; Accepted date: 19 August 2014; Published date: 31 August 2016 \\ Academic Editor: J. Judith Vijaya \\ Copyright (C) 2016. A. M. El-Sayed and S. M. Yakout. Distributed under Creative Commons CC-BY 4.0
}

\begin{abstract}
A comparative study on the sensing properties of nanoparticles $\mathrm{ZnO}+\mathrm{x}$ wt $\% \mathrm{CeO} 2$ and $\mathrm{SnO} 2+\mathrm{x}$ wt $\% \mathrm{CeO} 2(\mathrm{x}=0,2,4$ and 6$)$ sensors sintered at 400 oC toward ethanol gas have been carried out. The crystal structure and the particle size of the prepared samples were investigated by using XRD, IR and TEM techniques. XRD and IR investigation confirmed that the prepared ZnO and SnO2 have good crystalline character with average crystallite size of 34.5 and $7.2 \mathrm{~nm}$ respectively. The TEM study showed that the particles of the pure $\mathrm{ZnO}$ sensor nearly show a hexagonal shape which enhanced by the addition of $\mathrm{CeO} 2$. While the particles of the $\mathrm{SnO} 2$ sensors displayed fine structures with spherical shape. The electrical conductivity behavior of both oxides samples was nearly similar and the electrical conductivity values of $\mathrm{ZnO}$ sensors are higher than that of $\mathrm{SnO} 2$ sensors at the same conditions. The obtained gas sensing results showed that the $\mathrm{SnO} 2$ based sensors have high sensitivity values toward ethanol gas with lower operating temperature than that of $\mathrm{ZnO}$ based sensors. On the other hand, $\mathrm{ZnO}$ based sensors have slightly rapid response time and short recovery time than that of SnO2 based sensors.
\end{abstract}

Key words: $\mathrm{ZnO}$ nanoparticles; $\mathrm{SnO} 2$ nanoparticles; Ce-doping; ethanol gas sensors

\section{Introduction}

The detection of different types of gases and quantification of their precisely concentration have wide applications in different fields like domestic gas alarms, medical diagnostic equipment, industrial safety, environmental pollution, military field and food industry [Papadopoulos et al (1996), Wang C et al (2009), Wetchakun et al (2011), Brudzewski et al (2012), Mielle et al (2001) and Fleming (2001)]. With numerous industries that utilize or produce ethanol, it is apparent that reliable methods are needed

Cite this Article as: A.M. El-Sayed and S. M. Yakout (2016), "Highly Sensing Properties Sensors Based On Ce-Doped ZnO and SnO2 Nanoparticles to Ethanol Gas ", Journal of Research in Nanotechnology, Vol. 2016 (2016), Article ID 690025, DOI: 10.5171/2016.690025 
for its detection, monitoring and controlling. Ethanol gas detection with accurately quantification of its concentrations has broad applications in different areas such as monitoring of fermentation, foodstuffs conservering, breath analyzer of drivers to reduce the number of roads accidents caused by excessive alcohol consumption and medical processes [Neri et al (2006), de Lacy Costello et al 2002 and Hieu et al 2010]. Various methods can be used to detect ethanol gas including gas chromatographymass spectrometry, infrared spectroscopy, semiconductor gas sensors, and others [Pang et al 2001]. Ethanol gas sensors based on semiconductor metal oxide materials offer considerable advantages in comparison to other gas sensing methods [Korotcenkov 2007]. Nano-semiconductor metal oxide gas sensors are inexpensive to produce compared to other sensing technologies, small in size, reliable, fast response, easy to used and can be used in real field. Among the semiconductor metal oxides materials, $\mathrm{ZnO}$ and $\mathrm{SnO} 2$ are the two of the most widely materials used in gas sensing applications [Chaisitsak 2011 and Gupta et al 2010]. The advantages of the $\mathrm{ZnO}$ and $\mathrm{SnO} 2$ gas sensors are the high sensitivity, stability, novel shapes and low cost. The gas sensing mechanism of the metal oxides is depend on the interaction of tested gas with the preadsorbed oxygen species (02-, $0-$ and $02-$ ) on the oxide surface leading to the change in its electrical resistance [Kanan et al 2009 and Wang $L$ et al 2012]. The changes in the electrical resistance can be used as a measure of gas concentration. The gas sensing properties of the semiconductor metal oxide can be improved by preparing the material in the nano-sized range with high surface area which provides more surface active sites on which the gases adsorb and interact. Also, the sensing properties of the metal oxide gas sensor can be enhanced by the addition of some noble metals or other metal oxides [Liewhiran et al 2006, Lee et al 2009, Tianshu et al 1999, Li et al 2012 and Galatsis et al 2003]. Numerous researches have attempted to enhance the gas sensing characteristics of zinc oxide and tin oxide towards ethanol gas through using some additives such as $\mathrm{Pt}, \mathrm{Pd}, \mathrm{CoO}, \mathrm{Al} 2 \mathrm{O} 3$, CdO and Fe203 [Liewhiran et al 2006, Lee et al 2009, Tianshu et al 1999, Li et al 2012 and Galatsis et al 2003]. Rare earth oxides additions are well known to display a high surface basicity, fast oxygen ion mobility and interesting catalytic properties, these are thought to be important for enhancing gas sensing properties of the semiconductor materials [Tsang et al 1998]. The preparation methods, characterization and sensing properties to ethanol gas of $\mathrm{ZnO}+\mathrm{x}$ wt $\%$ $\mathrm{CeO} 2$ and $\mathrm{SnO} 2+\mathrm{x}$ wt\% $\mathrm{CeO} 2$ nanoparticles sensors samples sintered at different temperatures are presented elsewhere [ElSayed et al 2012 and Hassouna et al 2012]. The current study aims to compare between the samples which exhibited the best sensing characteristics at the same conditions to define the high sensing properties sensors to ethanol gas among the two oxides sensors.

\section{Experimental}

\section{Synthesis}

Zinc oxide nanoparticles were synthesized by chemical precipitation method using zinc acetate dihydrate (99.61\%) and diluted ammonium hydroxide as starting materials. The obtained precipitate was calcined in a muffle furnace at the temperature of $400 \mathrm{oC}$ for 4 hours and then left to cool to room temperature. Preparation of tin oxide nanoparticles was carried out also by chemical precipitation method using a solution of tin tetrachloride with concentration of $0.2 \mathrm{~mol} / \mathrm{L}$. The precipitate was then filtered and washed thoroughly until free of chloride by testing the filtrate with silver nitrate solution. The obtained precipitate was dried in air followed by calcination at $400 \mathrm{oC}$ for 4 hours then left to cool to room temperature. Appropriate amounts of $\mathrm{CeO} 2$ were added to the prepared $\mathrm{ZnO}$ and $\mathrm{SnO} 2$ nanoparticles powders with ratio of $0,2,4$ and 6 wt $\%$ for each. The resulting mixtures were ball milled for $2 \mathrm{~h}$ to get homogenous powder to be used as functional materials to fabricate sensors

A.M. El-Sayed and S. M. Yakout (2016), Journal of Research in Nanotechnology,

DOI: $10.5171 / 2016.690025$ 
pellets of $12 \mathrm{~mm}$ in diameter and $2 \mathrm{~mm}$ thick, followed by sintering at $400 \mathrm{oC}$ for 4 hours.

\section{Characterization and Measurements}

The prepared samples will be characterized by using X-ray diffraction analysis using Xray diffractometer (model-Bruker AXS D8 advance) with copper radiation, infrared transmission spectra using Nexus 670 FTIR spectrophotometer (Nicolet, USA) and transmission electron microscope using JEOL JEM-1230 operating at $120 \mathrm{KV}$ attached to CCD camera. a. c. electrical conductivity as well as ethanol gas sensing characteristics of the different sensors were measured in the temperature range from 30 up to $410 \mathrm{oC}$ using LCR meter (Hitester, model Hioki 3532, made in Japan) at frequency of $1 \mathrm{KHz}$ and applied $5 \mathrm{~V}$. The sample chamber was a closed glass cell contains the sensor sample surrounded by electrical cylindrical ceramic furnace with controlled temperature device [Hassona et al 2012]. The desired ethanol gas concentrations were obtained by injection a known volume of ethanol using a microsyringe through air tight rubber port into the glass chamber. The sensitivity (S) of the sensor toward ethanol gas was measured and calculated as the ratio of the electrical resistance in air atmosphere (Rair) to that in air containing ethanol gas (Rgas) by using the following relation [El-Sayed et al 2012 and Hassouna et al 2012].

$$
\mathrm{S}=\text { Rair } / \text { Rgas }
$$

\section{Results and Discussion}

\section{Characterization}

Fig. 1 shows the X-ray diffraction patterns of the prepared zinc oxide and tin oxide. All the diffraction peaks in the patterns can be indexed to hexagonal wurtzite structure of $\mathrm{ZnO}$ and tetragonal rutile structure of $\mathrm{SnO} 2$ which is in good agreement with the standard data (card file No. 36-1451 and card file No. 41-1445), respectively. The average crystallite size (D) of the prepared $\mathrm{ZnO}$ and
SnO2 powders are approximately $34.5 \mathrm{~nm}$ and $7.2 \mathrm{~nm}$ respectively. The X-ray diffraction investigations carried out on the prepared $\mathrm{ZnO}+\mathrm{x}$ wt $\% \mathrm{CeO} 2$ and $\mathrm{SnO} 2+\mathrm{x}$ wt\% $\mathrm{CeO} 2$ sensors and also all sensors sintered at $400 \mathrm{oC}$ confirmed that all the prepared samples are thermally stable and no chemical reaction occurred between $\mathrm{ZnO}$ or $\mathrm{SnO} 2$ and the $\mathrm{CeO} 2$ doping materials during the sintering processes. Fig. 2 depicts the averages values of the crystallite sizes of the $\mathrm{ZnO}+\mathrm{x} w \mathrm{wt} \% \mathrm{CeO} 2$ and $\mathrm{SnO} 2+\mathrm{x} w \mathrm{wt} \%$ $\mathrm{Ce} 02$ sensor samples sintered at $400 \mathrm{oC}$ respectively as estimated from the XRD measurement. In general, it was found that the averages of the crystallite sizes of $\mathrm{ZnO}$ sensors were higher than that of $\mathrm{SnO} 2$ sensors. Where, the averages of the crystallite sizes of pure and $\mathrm{CeO} 2$-doped $\mathrm{ZnO}$ sensors are ranging from 40.5 to $55 \mathrm{~nm}$, while that of pure and $\mathrm{CeO} 2$-doped $\mathrm{SnO} 2$ sensor samples are ranging from 11 to 19.2 $\mathrm{nm}$. For both oxides the crystallite size decreased with $\mathrm{CeO} 2$ additions. This indicates that the $\mathrm{CeO} 2$ doping material affects the rate of crystallite growth of $\mathrm{ZnO}$ and SnO2 [Jiang et al. 2010].

The infrared spectra of the prepared $\mathrm{ZnO}$ and SnO2 nanoparticles are shown in Fig. 3. With respect to the prepared $\mathrm{ZnO}$ sample, the absorption bands appeared at $\sim 3437,2924$, 1516 and $1389 \mathrm{~cm}-1$ were attributed to $\mathrm{O}-\mathrm{H}$ stretching mode of the absorbed water, $\mathrm{C}-\mathrm{H}$ mode of the acetate group, asymmetric and symmetric stretching modes of the carbonate group due to acetate group of stating materials, respectively [Maensiri et al 2006, Kwon et al 2002 and Rezende et al 2009]. The characteristic absorption band of the prepared zinc oxide was observed at $461 \mathrm{~cm}-1$, which attributed to stretching vibration of Zn-O bond [Maensiri et al 2006, Kwon et al 2002 and Rezende et al 2009]. In the case of $\mathrm{SnO} 2$ sample, Fig. 3(b), the absorption bands appeared at $\sim 3423$ and $1632 \mathrm{~cm}-1$ were assigned to stretching

A.M. El-Sayed and S. M. Yakout (2016), Journal of Research in Nanotechnology,

DOI: $10.5171 / 2016.690025$ 
vibration of $-\mathrm{OH}$ group and bending vibration of adsorbed molecular water. The characteristic tin oxide absorption bands were observed at 620 and $540 \mathrm{~cm}-1$ which ascribed to Sn-0-Sn stretching vibration of $\mathrm{SnO2}$ and terminal oxygen vibration of Sn$\mathrm{OH}$ groups, respectively [Adnan et al 2010 and Mariammal et al 2011]. The observed absorption bands due to adsorbed water and acetate group of starting materials (Fig.3) disappeared with sintering temperature.

The transmission electron microscope images of $\mathrm{ZnO}+\mathrm{x}$ wt $\% \mathrm{CeO} 2$ and $\mathrm{SnO} 2+\mathrm{x}$ wt $\% \mathrm{CeO} 2(\mathrm{x}=0,2,4$ and 6$)$ sensors sintered at $400 \mathrm{oC}$ are shown in Fig. 4. The particles of the pure $\mathrm{ZnO}$ sensor nearly show a hexagonal shape which enhanced by the addition of $\mathrm{CeO2}$. While the particles of the $\mathrm{SnO} 2$ sensors displayed fine structures with spherical shape. The averages particle sizes of both oxides samples were estimated and tabulated in Table 1. It can be seen that at the same $\mathrm{CeO} 2$ content the particle size of the $\mathrm{ZnO}$ sensors is larger than that of $\mathrm{SnO} 2$ sensors. For both oxides the average particle size were found to decrease with increasing $\mathrm{CeO} 2$ content as indicated in Table 1. These results show that $\mathrm{CeO} 2$ doping material may be acts as an inhibitor which resists the $\mathrm{ZnO}$ and $\mathrm{SnO} 2$ grain growth during the sintering temperature [Fen et al. 2007 and Maciel et al. 2003].

\section{Electrical Conductivity}

Fig. 5 shows the variation of the electrical conductivity with temperature for $\mathrm{ZnO}+\mathrm{x}$ wt $\% \mathrm{CeO} 2$ and $\mathrm{SnO} 2+\mathrm{x}$ wt $\% \mathrm{CeO} 2$ sensors sintered at 400 oC. In general, it can be seen that the electrical conductivity increases with temperature and the electrical conductivity behavior of both oxides samples is similar where this behavior is often seen in the case of semiconductor materials. All curves are divided into three different temperature regions denoted as $A B, B C$ and $C D$ which represent the thermal excitation of electron, adsorption of oxygen species and intrinsic semiconductor behavior, respectively [Caglar et al 2009, Sharma et al 2011 and Yu et al
2001]. Also, it can be seen that the electrical conductivity values of $\mathrm{ZnO}$ sensors are somewhat higher than that of $\mathrm{SnO} 2$ sensors at the same conditions. This may be due to the difference in the particle and change carriers concentration and its mobility.

\section{Ethanol Gas Sensing Properties}

Where the pure and cerium doped sensors of both oxides of $\mathrm{ZnO}$ and $\mathrm{SnO} 2$ sintered at 400 oC exhibited the highest sensitivity among all the prepared sensors, for that reason the study focused on these sensors. Fig. 6 illustrates the variation of the sensitivity with temperature towards $100 \mathrm{ppm}$ ethanol gas of $\mathrm{ZnO}+\mathrm{x}$ wt $\% \mathrm{CeO} 2$ and $\mathrm{SnO} 2+\mathrm{x} w \mathrm{t} \%$ $\mathrm{Ce} 02$ sensors sintered at $400 \mathrm{oC}$. With respect to the pure and $\mathrm{CeO} 2$-doped $\mathrm{ZnO}$ sensors, the sensitivity gradually increases with temperature and attains the maximum 310 oC (operating temperature), and then it decreases with increasing the temperature. While, the sensitivity of the pure and $\mathrm{CeO} 2$ doped $\mathrm{SnO} 2$ sensors gradually increase with temperature until 300 oC (operating temperature) and then after it decreased. For comparison, it can be seen that the $\mathrm{SnO} 2$ sensors have higher sensitivity values than that of $\mathrm{ZnO}$ sensors at the same conditions. Also, the operating temperature of the $\mathrm{SnO} 2$ sensors is lower than that in the case of $\mathrm{ZnO}$ sensors by $10 \mathrm{oC}$.

The mechanism of the ethanol detection on the both oxides sensors is depending on the interaction of ethanol gas with the preadsorbed oxygen species on the oxides surface. Where, in atmospheric air the surfaces of $\mathrm{ZnO}$ or $\mathrm{SnO} 2$ sensors are covered by oxygen species. At relatively low temperature $\left(<\begin{array}{ll}150 & \text { oC }\end{array}\right)$ the molecular oxygen species (02-) are adsorbed and with increasing the operating temperature the molecular oxygen dissociate to ionic oxygen species $\quad(02-\rightarrow 20-\rightarrow 02-)$ and its concentration raise gradually until certain temperature by extracting electrons from the metal oxide material which increase the electrical resistance of the materials. The ionic oxygen species $\mathrm{O}-$ and $02-$ are the

A.M. El-Sayed and S. M. Yakout (2016), Journal of Research in Nanotechnology,

DOI: $10.5171 / 2016.690025$ 
more reactive species in gas sensing process. When the sensors surface exposed to ethanol gas co-adsorption and mutual interaction between the ethanol gas and the adsorb oxygen species with liberating electrons to the sensors materials which decreases the electrical resistance and the final reaction [El-Sayed et al 2012 and Hassouna et al 2012]:

$\mathrm{C} 2 \mathrm{H} 5 \mathrm{OH}+$
$2 \mathrm{CO} 2+3 \mathrm{H} 2 \mathrm{O}+6 \mathrm{e}$
Or

$\begin{array}{lr}\mathrm{C} 2 \mathrm{H} 5 \mathrm{OH}+ & 6 \mathrm{O} 2- \\ 2 \mathrm{CO} 2+3 \mathrm{H} 2 \mathrm{O}+12 \mathrm{e} & (3)\end{array}$

Where, the changes in the electrical resistance of the sensors in the air to that in gas atmosphere (Rair/Rgas) represent the sensitivity of the sensors to the tested gas.

The dependence of the sensitivity on $\mathrm{CeO} 2$ content of $\mathrm{ZnO}$ and $\mathrm{SnO} 2$ sensors sintered at $400 \mathrm{oC}$ is shown in Fig. 7. It was found that 4 wt \% $\mathrm{CeO} 2$ doping is the more suitable concentration to enhance the sensitivity of $\mathrm{ZnO}$ sensor towards ethanol gas. The $\mathrm{CeO} 2$ additions to $\mathrm{ZnO}$ sensors up to $4 \mathrm{wt} \%$ can promote the ethanol dehydrogenation reaction in the form of catalysts and improve $\mathrm{ZnO}$ surface basicity which enhances the sensitivity towards ethanol gas [El-Sayed et al 2012]. . On the other hand, the increasing in $\mathrm{CeO} 2$ doping concentration to 6 wt \% may be cause a high covering of $\mathrm{ZnO}$ surface which reduce the available adsorption sites on $\mathrm{ZnO}$ surface and leads to the observed decrease in the sensitivity [Hamedani et al. 2012]. While $2 \mathrm{wt} \% \mathrm{CeO} 2$ doing is the more suitable concentration to enhance the sensitivity of $\mathrm{SnO} 2$ sensors towards ethanol gas. The additions of 2 wt \% $\mathrm{CeO} 2$ to $\mathrm{SnO} 2$ seem to be benefit for ethanol dehydrogenation on the surface of the sensor sample [Hassona et al 2012]. Above 2 wt \%, $\mathrm{CeO} 2$ content the available adsorption sites on the $\mathrm{SnO} 2$ sensor surface may be reduced which worsen the gas-sensing properties [Pourfayaz et al. 2008].
The variation of the sensitivity with ethanol gas concentration for $\mathrm{ZnO}+4 \mathrm{wt} \% \mathrm{CeO} 2$ and $\mathrm{SnO} 2+2$ wt $\% \mathrm{CeO} 2$ sensors sintered at 400 oC is shown in Fig. 8. For $\mathrm{ZnO}+4$ wt \% $\mathrm{CeO} 2$ the sensitivity linearly increases with increasing the concentration of ethanol gas up to $400 \mathrm{ppm}$. While, above $400 \mathrm{ppm}$, the sensitivity slowly increased. On the other hand, the $\mathrm{SnO} 2+2$ wt \% $\mathrm{CeO} 2$ sensor shows a linear increasing in the sensitivity up to $500 \mathrm{ppm}$ then after it slowly increases with increasing the gas concentration until 2000 ppm.

The response time of the sensor is usually defined as the time taken to achieve at least $90 \%$ of the final change in its electrical resistance during exposure to the tested gas. While, the recovery time is generally defined as the time taken by the sensor to get back at least $90 \%$ of its original state after reexposure to air ambient by maintaining the operating temperature constant [Hassona et al 2012]. The variation of the sensitivity with time of $\mathrm{ZnO}+4$ wt \% $\mathrm{CeO} 2$ and $\mathrm{SnO} 2+2$ wt $\% \mathrm{CeO} 2$ sensors sintered at 400 oC after exposure to $100 \mathrm{ppm}$ ethanol gas is shown in Fig. 9. It was found that, the response time of $\mathrm{ZnO}+4$ wt \% $\mathrm{CeO} 2$ sensor was 12 second while that of $\mathrm{SnO} 2+2 \mathrm{wt} \% \mathrm{CeO} 2$ sensor was 20 second. Fig. 10 illustrates the variation of the sensitivity with time of $\mathrm{ZnO}+4 \mathrm{wt} \%$ $\mathrm{CeO} 2$ and $\mathrm{SnO} 2+2$ wt \% $\mathrm{CeO} 2$ sensors sintered at $400 \mathrm{oC}$ after re-exposure to air atmosphere. It can be seen that, the recovery times of $\mathrm{ZnO}+4$ wt \% $\mathrm{CeO} 2$ and $\mathrm{SnO} 2+2$ wt $\% \mathrm{CeO} 2$ sensors were 10 and 15 second, respectively. The above mentioned results revealed that all the investigated sensors samples are chemically stable i.e there is no chemical reactions occurred between the sensors and the tested gas led to the change in the chemical composition of the sensors during the exposure to ethanol gas.

\section{Conclusions}

From the obtained data it can be concluded that the best sensors among the prepared sensors of the two oxides are $\mathrm{ZnO}+4 \mathrm{wt} \%$ $\mathrm{CeO} 2$ and $\mathrm{SnO} 2+2$ wt $\% \mathrm{CeO} 2$ sensors

A.M. El-Sayed and S. M. Yakout (2016), Journal of Research in Nanotechnology,

DOI: $10.5171 / 2016.690025$ 
sintered at 400 oC. The $\mathrm{SnO} 2+2 \mathrm{wt} \% \mathrm{CeO} 2$ sensor has high sensitivity towards ethanol gas, rapid response time (20s) and short recovery time (15s) with operating temperature of $300 \mathrm{oC}$. Also, $\mathrm{ZnO}+4 \mathrm{wt} \%$
CeO2 sensor has high sensitivity towards ethanol gas, rapid response time (12s) and short recovery time (10s) with operating temperature of 310
oC.

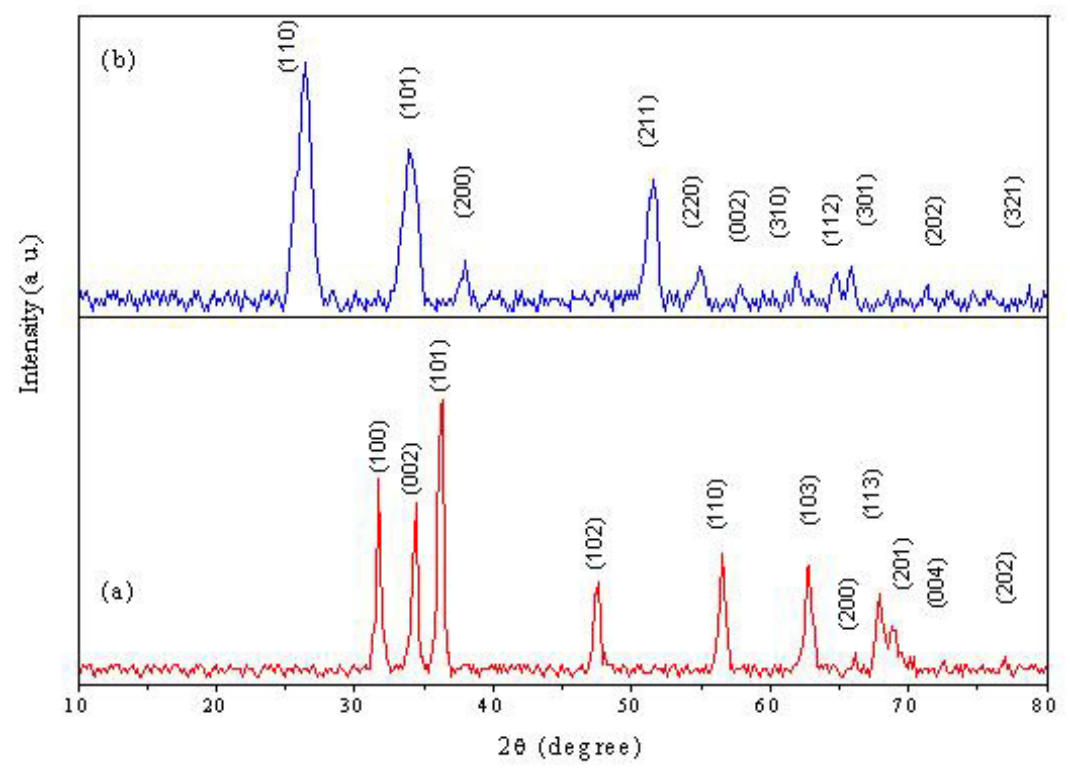

Figure 1: X-ray diffraction patterns of (a): prepared $\mathrm{ZnO}$ and (b): prepared $\mathrm{SnO}_{2}$ nanoparticles sintered at $400{ }^{\circ} \mathrm{C}$.
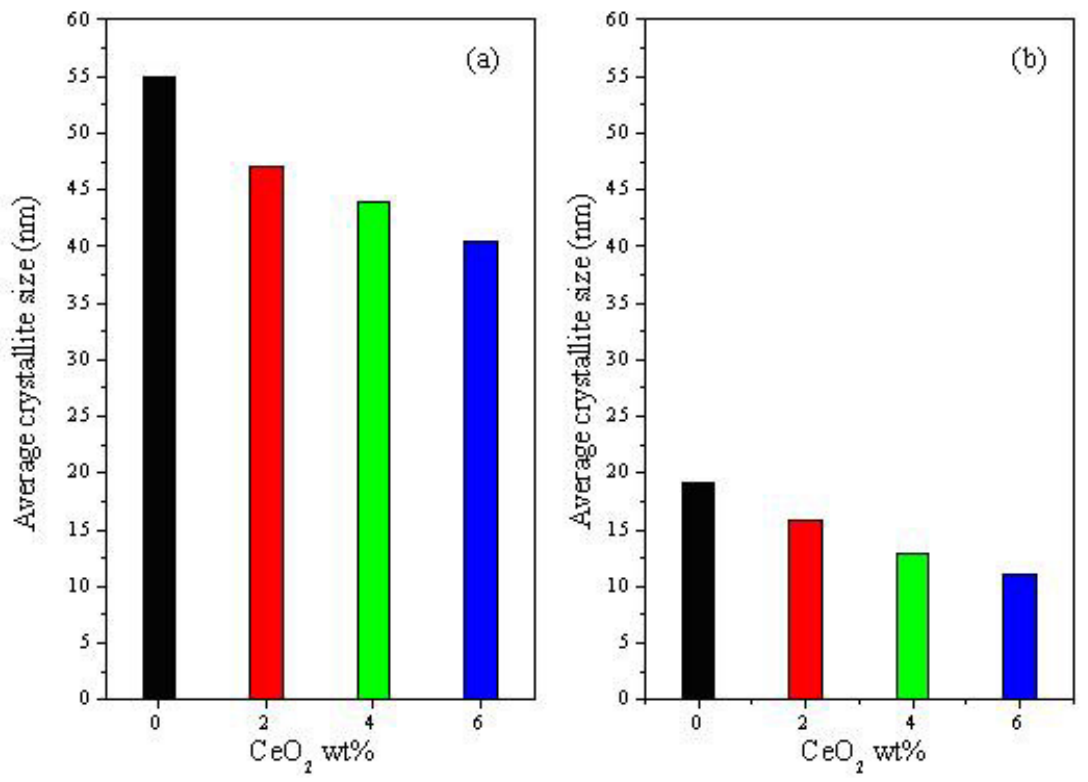

Figure 2: The averages values of the crystallite size of (a): $\mathrm{ZnO}+\mathrm{x} \mathrm{wt} \% \mathrm{CeO}_{2}$ and (b): $\mathrm{SnO}_{2}+\mathrm{x}$ wt $\% \mathrm{CeO}_{2}$ sensors sintered at $400{ }^{\circ} \mathrm{C}$, where $\mathrm{x}=0,2,4$ and 6 .

A.M. El-Sayed and S. M. Yakout (2016), Journal of Research in Nanotechnology, 


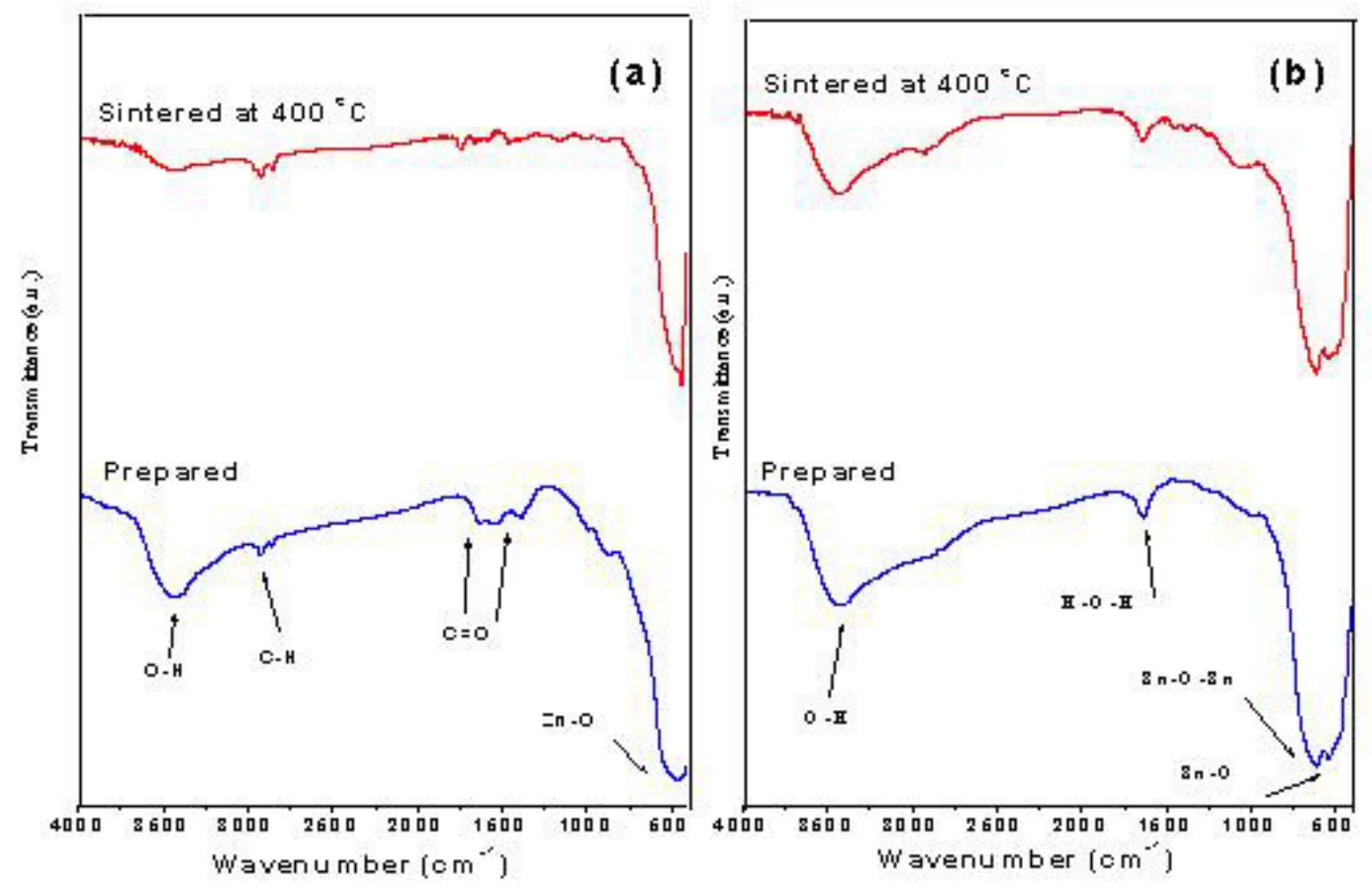

Figure 3: Infrared spectra of (a): prepared and sintered ZnO nanoparticles samples and (b): prepared and sintered $\mathrm{SnO}_{2}$ nanoparticles samples.

A.M. El-Sayed and S. M. Yakout (2016), Journal of Research in Nanotechnology, DOI: $10.5171 / 2016.690025$ 

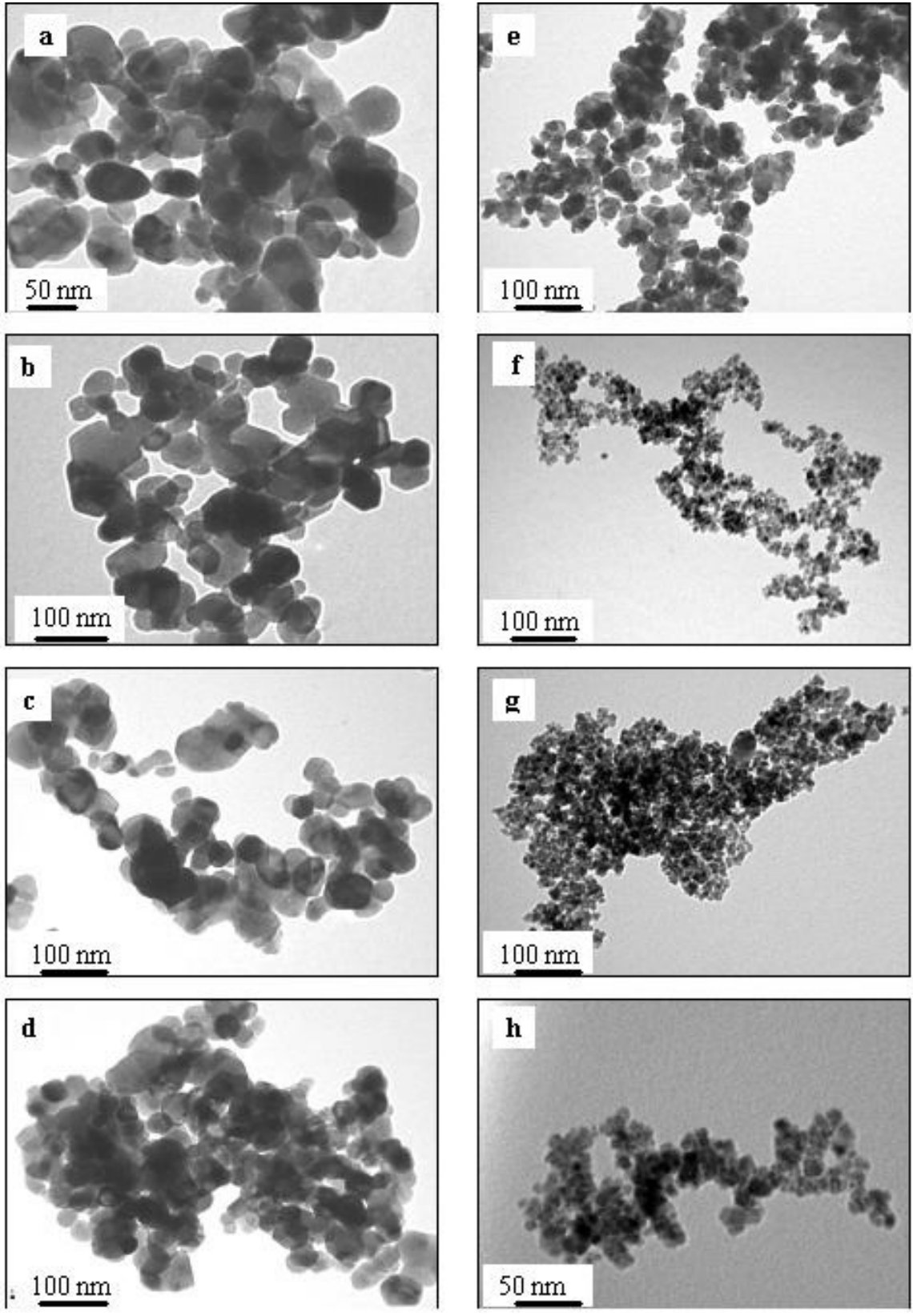

Figure 4: TEM images of $\mathrm{ZnO}+\mathrm{x}$ wt $\% \mathrm{CeO}_{2}$ sensors where (a) $\mathrm{x}=0$, (b) $\mathrm{x}=2$, (c) $\mathrm{x}=4$ and (d) $\mathrm{x}=6$, and $\mathrm{SnO}_{2}+\mathrm{x}$ wt $\% \mathrm{CeO}_{2}$ where (e) $\mathrm{x}=0$, (f) $\mathrm{x}=2$, (g) $\mathrm{x}=4$ and (h) $\mathrm{x}=6$ sensors sintered at $400{ }^{\circ} \mathrm{C}$. 

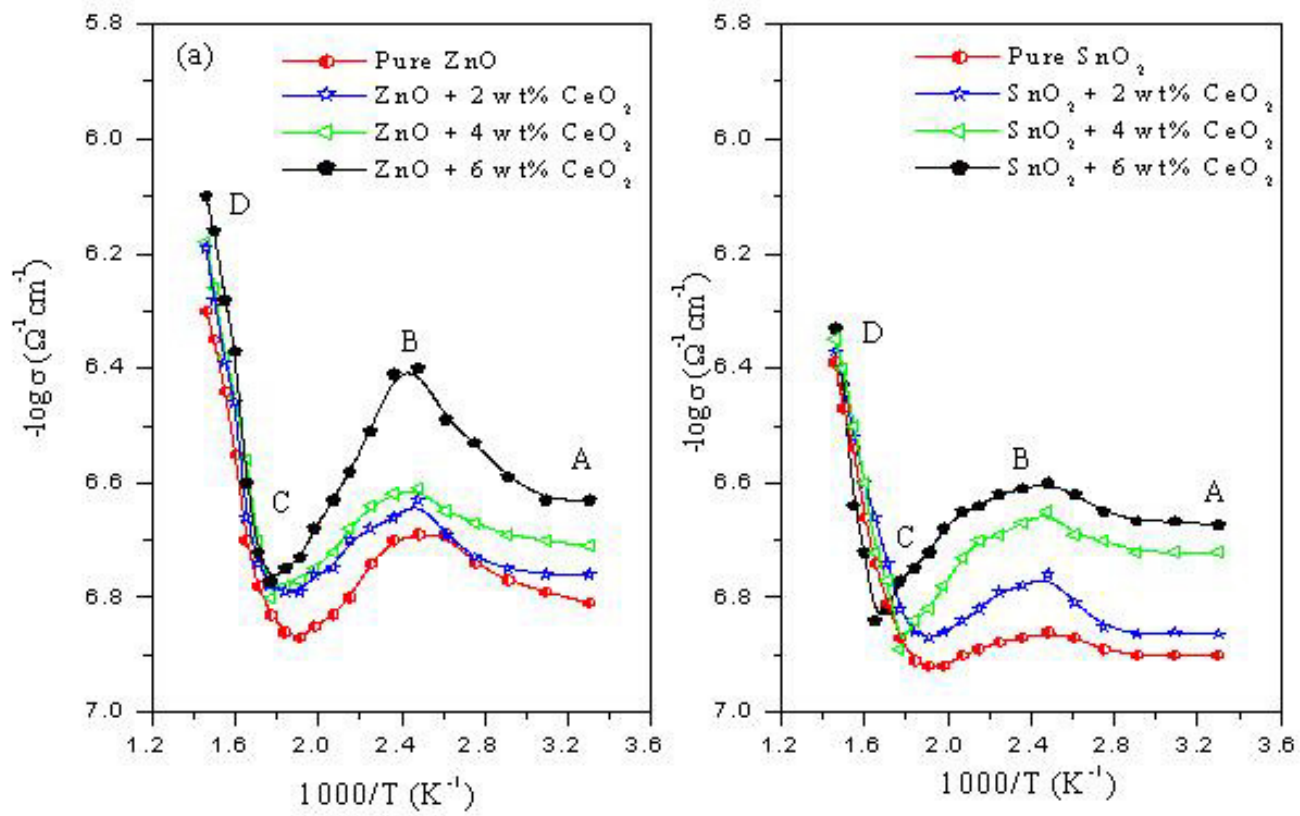

Figure 5: The variation of the electrical conductivity with temperature of (a): $\mathrm{ZnO}+\mathrm{x}$ wt\% $\mathrm{CeO}_{2}$ and (b): $\mathrm{SnO}_{2}+\mathrm{x}$ wt\% $\mathrm{CeO}_{2}$ sensors sintered at $400{ }^{\circ} \mathrm{C}$.
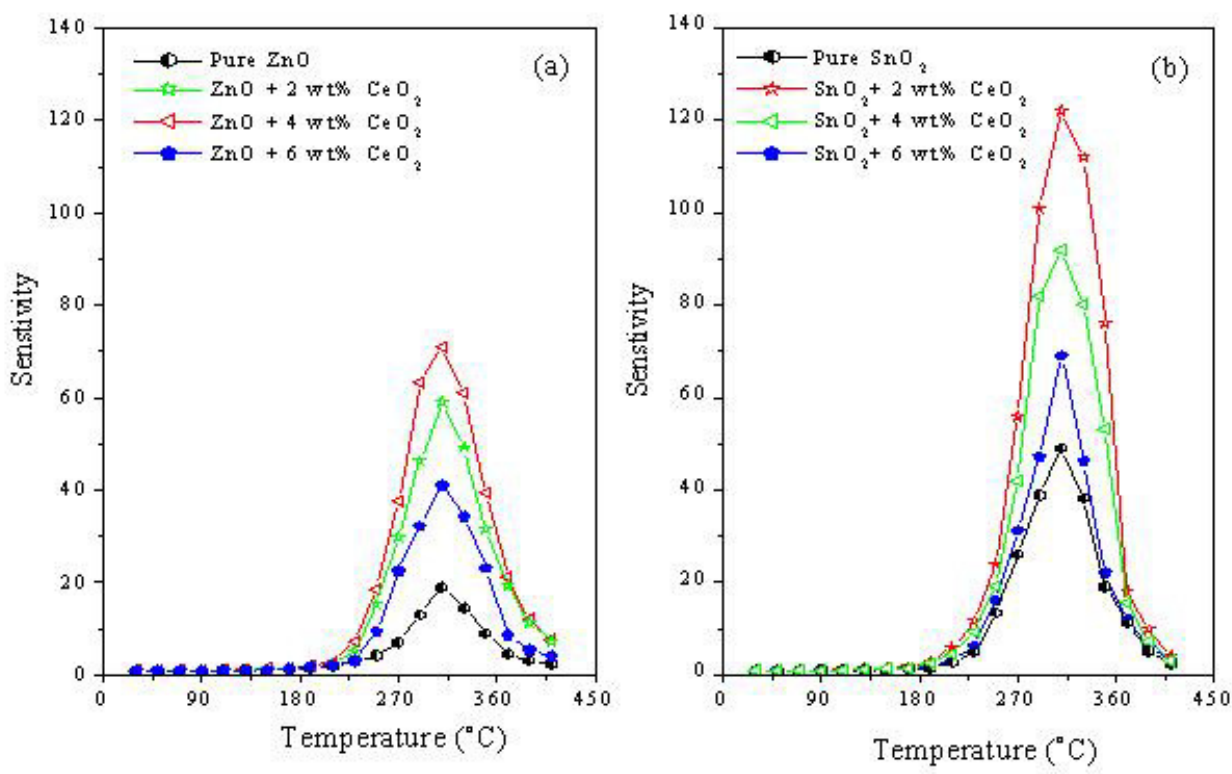

Figure 6: The variation of the sensitivity with temperature of (a): $\mathrm{ZnO}+\mathrm{x} \mathrm{wt} \% \mathrm{CeO}_{2}$ and (b): $\mathrm{SnO}_{2}+\mathrm{x}$ wt $\% \mathrm{CeO}_{2}$ sensors sintered at $400{ }^{\circ} \mathrm{C}, 100 \mathrm{ppm}$ ethanol gas.

A.M. El-Sayed and S. M. Yakout (2016), Journal of Research in Nanotechnology,

DOI: $10.5171 / 2016.690025$ 

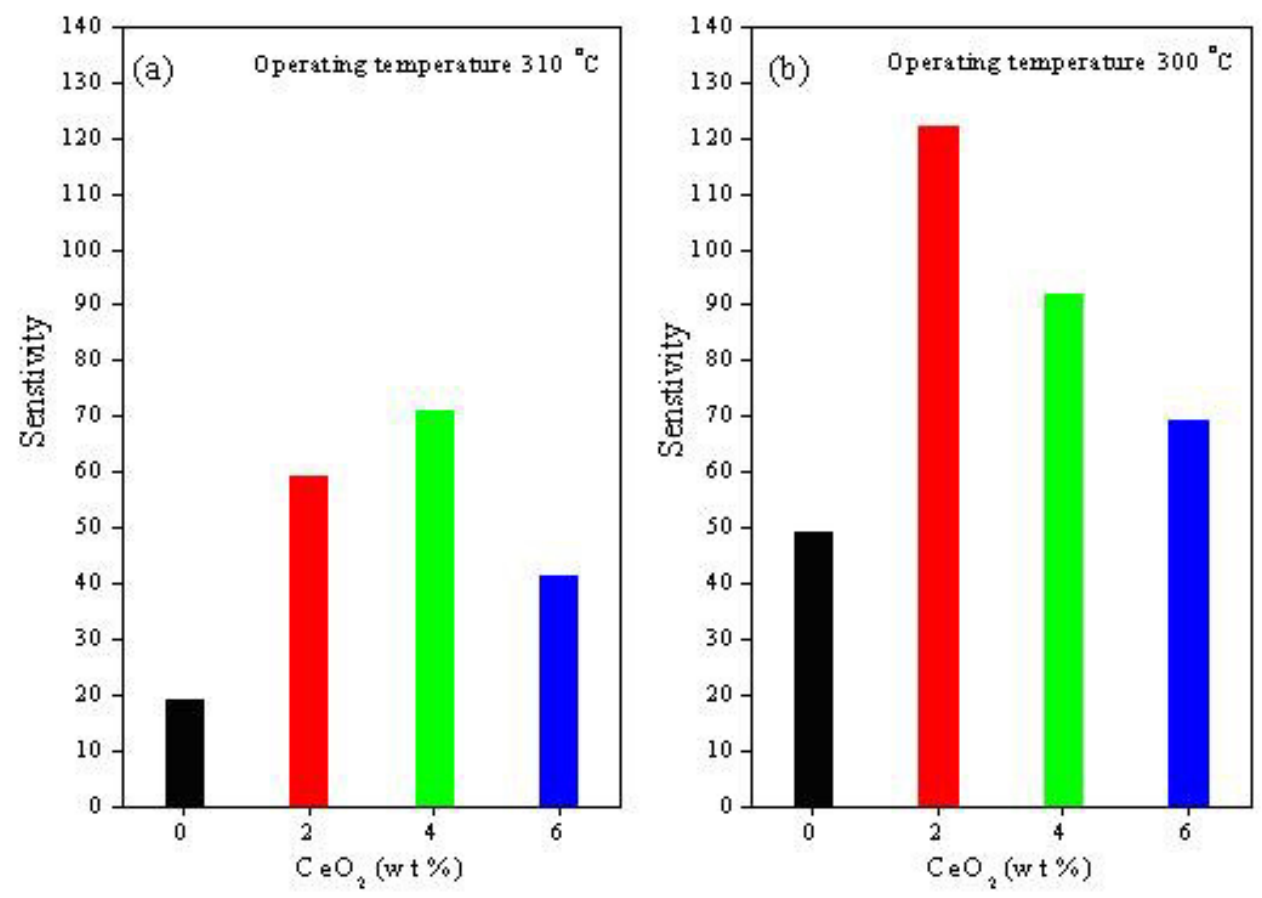

Figure7: The dependence of the sensitivity on $\mathrm{CeO}_{2}$ content of (a): $\mathrm{ZnO}+\mathrm{x}$ wt\% $\mathrm{CeO}_{2}$ and (b): $\mathrm{SnO}_{2}+\mathrm{x}$ wt $\% \mathrm{CeO}_{2}$ sensors sintered at $400{ }^{\circ} \mathrm{C}$, where $\mathrm{x}=0,2,4$ and 6 .

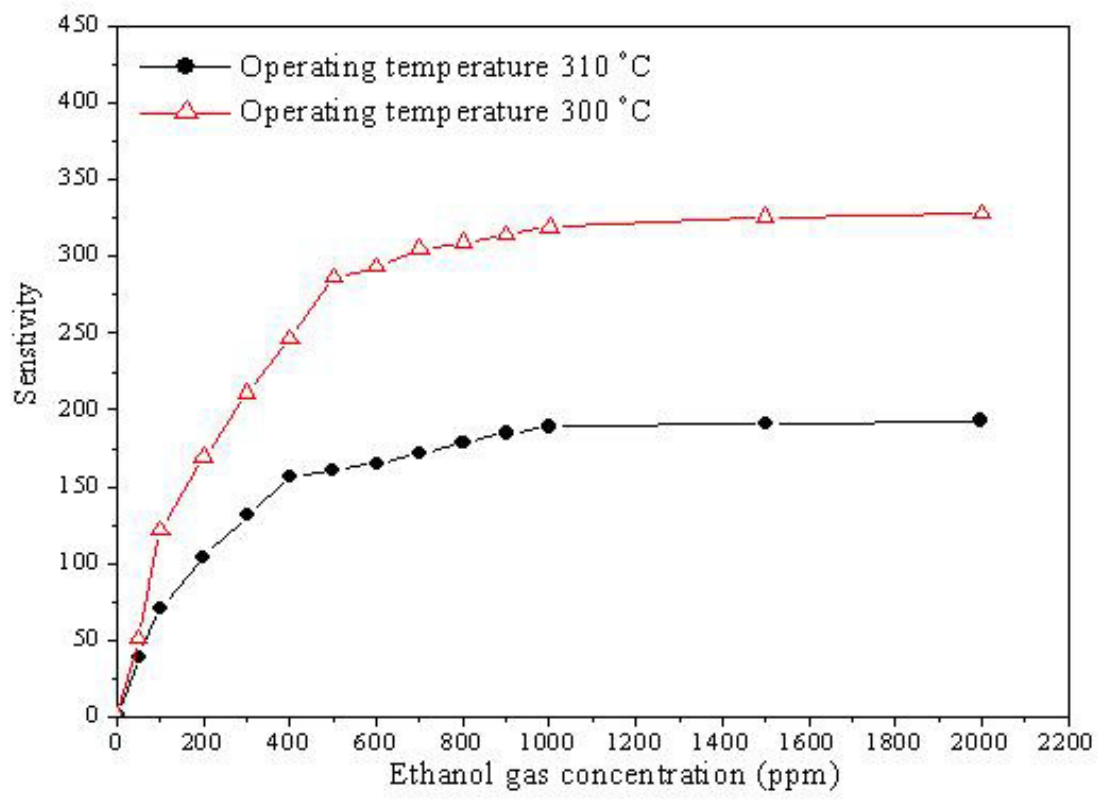

Figure 8: The variation of the sensitivity with ethanol gas concentration for $(\bullet): \mathrm{ZnO}+4 \mathrm{wt}$ $\% \mathrm{CeO}_{2}$ and $(\Delta): \mathrm{SnO}_{2}+2 \mathrm{wt} \% \mathrm{CeO}_{2}$ sensors sintered at $400{ }^{\circ} \mathrm{C}$.

A.M. El-Sayed and S. M. Yakout (2016), Journal of Research in Nanotechnology, DOI: $10.5171 / 2016.690025$ 


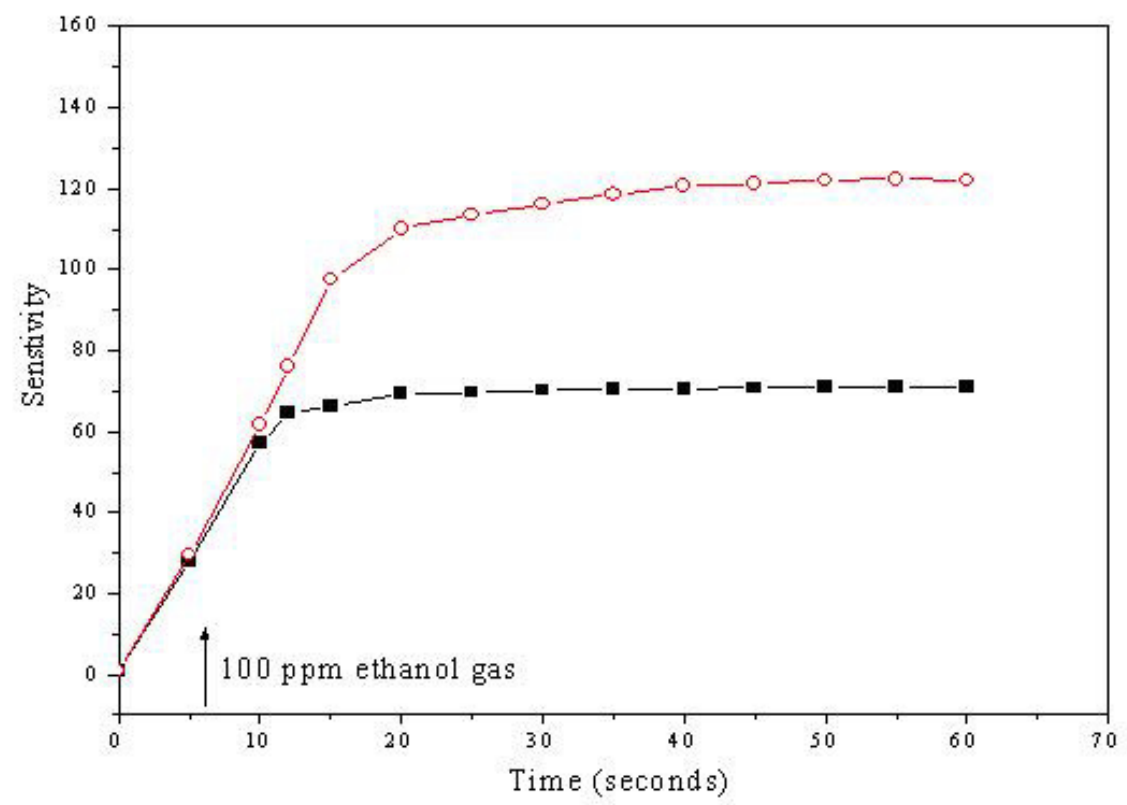

Figure 9: The variation of the sensitivity with time of (-) $\mathrm{ZnO}+4 \mathrm{wt} \% \mathrm{CeO}_{2}$ (operating temperature $310{ }^{\circ} \mathrm{C}$ ) and $(\circ) 32 \mathrm{SnO}_{2}+2 \mathrm{wt} \% \mathrm{CeO}_{2}$ (operating temperature $300{ }^{\circ} \mathrm{C}$ ) sensors sintered at $400{ }^{\circ} \mathrm{C}$ during exposure to ethanol gas.

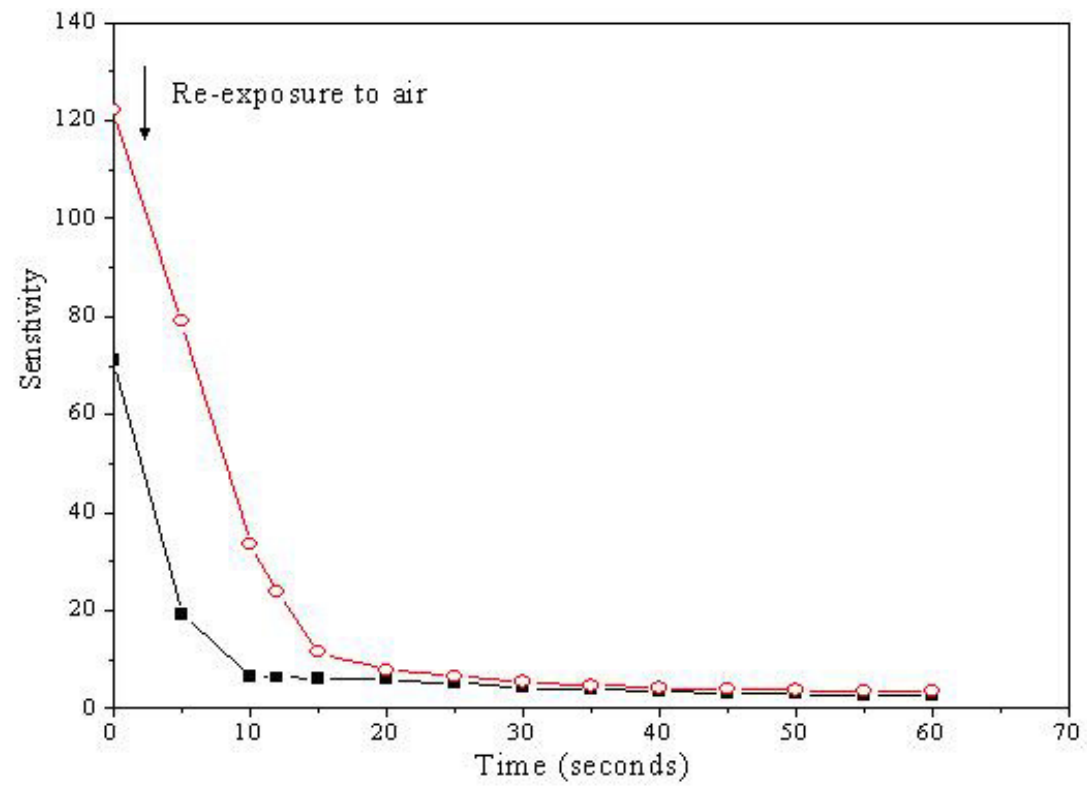

Figure 10: The variation of the sensitivity with time of (a) $\mathrm{ZnO}+4 \mathrm{wt} \% \mathrm{CeO}_{2}$ (operating temperature $310{ }^{\circ} \mathrm{C}$ ) and $(\mathrm{O}) \mathrm{SnO}_{2}+2 \mathrm{wt} \% \mathrm{CeO}_{2}$ (operating temperature $300{ }^{\circ} \mathrm{C}$ ) sensors sintered at $400{ }^{\circ} \mathrm{C}$ after re-exposure to air atmosphere.

A.M. El-Sayed and S. M. Yakout (2016), Journal of Research in Nanotechnology,

DOI: $10.5171 / 2016.690025$ 


\section{References}

1. Adnan, R. Razana, N. A. Abdul Rahman, I. and Farrukh, M. A. (2010) "Synthesis and characterization of high surface area tin oxide nanoparticles via the sol-gel method as a catalyst for the hydrogenation of styrene" Journal of the Chinese Chemical Society, 57 (2) 222-229.

2. Brudzewski, K. Osowski, S. and Pawlowski, W. (2012) "Metal oxide sensor arrays for detection of explosives at subparts-per million concentration levels by the differential electronic nose" Sensors and Actuators B, 161 (1) 528-533.

3. Caglar, M. Ilican, S. Caglar, Y. and Yakuphanoglu, F. (2009) "Electrical conductivity and optical properties of $\mathrm{ZnO}$ nanostructured thin film" Applied Surface Science, 255(8) 4491-4496.

4. Chaisitsak, S. (2011) "Nanocrystalline SnO2:F thin films for liquid petroleum gas sensors" Sensors, 11 (7) 7127-7140.

5. de Lacy Costello, B. P. J. Ewen, R. J. Guernion, N. and Ratcliffe, N. M. (2002) "Highly sensitive mixed oxide sensors for the detection of ethanol" Sensors and Actuators B, 87 (1) 207-210.

6. El-Sayed, A. M. Ismail, F. M. Khder, M. H. Hassouna, M. E. M. and Yakout, S. M. (2012) "effect of $\mathrm{CeO} 2$ doping on the structure, electrical conductivity and ethanol gas sensing properties of nanocrystalline $\mathrm{ZnO}$ sensor" International journal on smart sensing and intelligent systems, 5 (3) 606623.

7. Fen, L. Bo, Y. Jie, Z. Anxi, J. Chunhong, S. Xiangji, K. and Xin, W. (2007) "Study on desulfurization efficiency and products of Cedoped nanosized $\mathrm{ZnO}$ desulfurizer at ambient temperature" Journal of Rare Earths, 25 (3) 306-310.
8. Fleming, W. J. (2001) "Overview of Automotive Sensors" IEEE Sensors Journal, 1 (4) 296-308.

9. Galatsis, K. Cukrov, L. Wlodarski, W. McCormick, P. Kalantar-zadeh, K. Comini, E. and Sberveglieri, G. (2003) "P- and n-type Fedoped $\mathrm{SnO} 2$ gas sensors fabricated by the mechanochemical processing technique" Sensors and Actuators B, 93 (1-3) 562-565.

10. Gupta, S. K. Joshi, A. and Kaur, M. (2010) "Development of gas sensors using $\mathrm{ZnO}$ nanostructures" Journal of Chemical Sciences, 122 (1) 57-62.

11. Hamedani, N. F. Mahjoub, A. R. Khodadadi, A. A. and Mortazavi, Y. (2012) "CeO2 doped ZnO Flower-like Nanostructure sensor selective to ethanol in presence of $\mathrm{CO}$ and CH4" Sensors and Actuators B, 169 (5) 67-73.

12. Hassouna, M. E. M. El-Sayed, A. M. Ismail, F. M. Khder, M. H. Farghali, A. A. and Yakout, S. M. (2012) "Investigation on the structure, electrical conductivity and ethanol gas sensitive properties of Ce-doped $\mathrm{SnO} 2$ nanoparticles sensors" International Journal of Nanomaterials and Biostructures, 2 (0 4449.

13. Hieu, N. V. Duc, N. A. P. Trung, T. Tuan, M. A. and Chien, N. D. (2010) "Gas-sensing properties of tin oxide doped with metal oxides and carbon nanotubes: A competitive sensor for ethanol and liquid petroleum gas" Sensors and Actuators B, 144 (2) 450-456.

14. Jiang, Z. Guo, Z. Sun, B. Jia, Y. Li, M. and Liu, J. (2010) "Highly sensitive and selective butanone sensors based on cerium-doped SnO2 thin films" Sensors and Actuators B, 145 (2) 667-673.

15. Kanan, S. M. El-Kadri, O. M. Abu-Yousef, I. A. and Kanan, M. C. (2009) "Semiconducting metal oxide based sensors for selective gas pollutant detection" Sensors, 9 (10) 81588196.

A.M. El-Sayed and S. M. Yakout (2016), Journal of Research in Nanotechnology, DOI: $10.5171 / 2016.690025$ 
16. Korotcenkov, G. (2007) "Metal oxides for solid-state gas sensors: What determines our choice?" Materials Science and Engineering B, 139 (1) 1-23.

17. Kwon, Y. J. Kim, K. H. Lim, C. S. and Shim, K. B. (2002) "Characterization of $\mathrm{ZnO}$ nanopowders synthesized by the polymerized complex method via an organochemical route" Journal of Ceramic Processing Research, 3 (3) 146-149.

18. Lee, Y. I. Lee, K. J. Lee, D. H. Jeong, Y. K. Lee, H. S. and Choa, Y. H. (2009) "Preparation and gas sensitivity of $\mathrm{SnO} 2$ nanopowder homogenously doped with Pt nanoparticles" Current Applied Physics, 9 (1) 579-581.

19. Li, Y. J. Li, K. M. Wang, C. Y. Kuo, C. I. and Chen, L. J. (2012) "Low-temperature electrodeposited Co-doped $\mathrm{ZnO}$ nanorods with enhanced ethanol and CO sensing properties" Sensors and Actuators B, 161 (1) 734-739.

20. Liewhiran, C. and Phanichphant, S. (2006) "Effects of Palladium loading on the Response of a Thick Film Flame-made $\mathrm{ZnO}$ Gas Sensor for Detection of Ethanol Vapor" Sensors, 7 (7) 1159-1184.

21. Maciel, A. P. Lisboa-Filho, P. N. Leitea, E. R. Paiva-Santos, C. O. Schreiner, W. H. Maniette, Y. and Longo, E. (2003) "Microstructural and morphological analysis of pure and Ce-doped tin dioxide nanoparticles" Journal of the European Ceramic Society, 23 (5) 707-713.

22. Maensiri, S. Laokul, P. and Promarak, V. (2006) "Synthesis and optical properties of nanocrystalline $\mathrm{ZnO}$ powders by a simple method using zinc acetate dihydrate and poly(vinyl pyrrolidone)" Journal of Crystal Growth, 289 (1) 102-106.

23. Mariammal, R. N. Rajamanickam, N. and Ramachandran, K. (2011) "Synthesis and characterization of undoped and Co-doped SnO2 nanoparticles" Journal of NanoElectronic Physics, 3 (1) 92-100.
24. Mielle, P. and Marquis, F. (2001) "Onesensor electronic olfactometer for rapid sorting of fresh fruit juices" Sensors and Actuators B, 76 (1-3) 470-476.

25. Neri, G. Bonavita, A. Micali, G. Donato, N. Deorsola, F. A. Mossino, P. Amato, I. and De Benedetti, B. (2006) "Ethanol sensors based on Pt-doped tin oxide nanopowders synthesised by gel-combustion" Sensors and Actuators B, 117 (1) 196-204.

26. Pang, C. C. Chen, M. H. Lin, T. Y. and Chou, T. C. (2001) "An amperometric ethanol sensor by using nickel modified carbon-rod electrode" Sensors and Actuators B, 73 (2-3) 221-227.

27. Papadopoulos, C. A. Vlaehos, D. S. and Avaritsiotis, J. N. (1996) "Comparative study of various metal-oxide-based gas-sensor architectures" Sensors and Actuators B, 32 (1) 61-69.

28. Pourfayaz, F. Mortazavi, Y. Khodadadi, A. and Ajami, S. (2008) "Ceria-doped SnO2 sensor highly selective to ethanol in humid air" Sensors and Actuators B, 130 (2) 625629.

29. Rezende, C. P. da Silva, J. B. and Mohallem, N. D. S. (2009) "Influence of Drying on the Characteristics of Zinc Oxide Nanoparticles" Brazilian Journal of Physics, 39 (1) 248-251.

30. Sharma, A. Tomar, M. and Gupta, V. (2011) "SnO2 thin film sensor with enhanced response for NO2 gas at lower temperatures" Sensors and Actuators B, 156 (2) 743-752.

31. Tianshu, Z. Hing, P. Li, Y. and Jiancheng, Z. (1999) "Selective detection of ethanol vapor and hydrogen using Cd-doped $\mathrm{SnO} 2$ based sensors" Sensors and Actuators B, 60 (2) 208-215.

32. Tsang, S. C. and Bulpitt, C. (1998) "Rare earth oxide sensors for ethanol analysis" Sensors and Actuators B, 52 (3) 226-235.

A.M. El-Sayed and S. M. Yakout (2016), Journal of Research in Nanotechnology,

DOI: $10.5171 / 2016.690025$ 
33. Wang, C. and Sahay, P. (2009) " Breath analysis using laser spectroscopic techniques: breath biomarkers, spectral fingerprints, and detection limits" Sensors, 9 (10) 8230-8262.

34. Wang, L. Kang, Y. Liu, X. Zhang, S. Huang, W. and Wang, S. (2012) "ZnO nanorod gas sensor for ethanol detection" Sensors and Actuators B, 162 (1) 237- 243.
35. Wetchakun, K. Samerjai, T. Tamaekong, N. Liewhiran, C. Siriwong, C. Kruefu, V. Wisitsoraat, A. Tuantranont, A. and Phanichphant, S. (2011) " Semiconducting metal oxides as sensors for environmentally hazardous gases" Sensors and Actuators B, 160 (1) 580-591.

36. Yu, J. H. and Choi, G. M. "Selective CO gas detection of $\mathrm{CuO}$ - and $\mathrm{ZnO}$-doped $\mathrm{SnO} 2$ gas sensor" Sensors and Actuators B, 75 (1-2) 56-61(2001).

A.M. El-Sayed and S. M. Yakout (2016), Journal of Research in Nanotechnology, 